\title{
Jiashe's Status in Patriarchal Clan System and His Subtle Relationship With Jiazheng in Hongloumeng
}

\author{
Guofu Xu \\ College of Literature and Journalism, Sichuan University, Chengdu, Sichuan, China \\ shendu1228@163.com
}

Keywords: Jiashe and Jiazheng, Cao Family, Textual Logicality, Fiction, Exploring History, The New School About Hongloumeng

\begin{abstract}
The new school about Hongloumeng holds the idea that the characters in the fiction are real historical figures, so they can find out some clues via the mutual supporting by the novel and history in some ways. In this view, they always draw fraudulent conclusions. They deliberately exaggerate the similarities and ignore the contradictions between the plots and real history. In order to solve some unavoidable problems and bolster their viewpoints, they always distort context. The readers push the novel to the back burner because they become historians automatically. They prefer exploring history rather than enjoying the plots. When historians regard the fiction as the Caos' real words and deeds, they will cause a series of problems, even absurd conclusions. In fact, the fiction gives detailed explanation about Jiashe' s status in patriarchal clan system and his subtle relationship with Jiazheng.
\end{abstract}

\section{1. 引言}

《红楼梦》将贾赦、贾政两人的关系处理的十分微妙，但在新红学“曹贾互证”的解读方法 出现之前，很少有人对赦、政的关系有过疑惑，盖因作者批阅十载、增删五次，小说自是思维缜 密，故文本上下并不存在矛盾和难解之处。赦政关系的种种疑问是伴随着新红学的实证出现的。 新红学不自觉的把小说看成实录，用历史的逻辑去解读小说，历史与小说种种矛盾、不合之处就 用想象和假设来填补。以致破坏了小说自身的逻辑性，导致钻之愈深，矛盾愈多。换句话说，赦 政的疑问是在曹家与贾家、历史与文本的比附过程中产生的。这正是鲁迅所说的 “盖叙述皆存本 真，闻见悉所亲历，正因写实，转成新鲜。而世人忽略此言，每欲别求深义，揣测之说，久而遂 多。”[1]

对于这些 “难懂”之处，周汝昌先生作了总结：第一，他（贾赦）的住处不好懂；第二，贾 赦与贾母的关系不好懂; 第三, 人们嘴里的话不好懂[2]。当然最让人感到不解的还是贾赦、贾 政的住处，贾赦作为贾府的嫡长子袭承了荣府的爵位，理应是荣国府的主人，但问题是住在荣府 的偏偏却是贾政，贾赦只是居住在偏房里。

\section{2. 源于新红学 “曹贾互证” 的种种假设}

新红学的开创者胡适坚持“自传说”，其在《红楼梦考证》中用曹家与贾家进行双向互证， 认为贾家就是曹家。“曹寅死后，曹颙袭织造之职。到康熙五十四年，曹颙或是死了，或是因事 撤换了，故次子曹煩接下去做……《氏族通谱》上只称曹寅为通政使，称曹煩为员外郎。但《红 楼梦》里的贾政，也是次子，也是先不袭爵，也是员外郎。这三层都与曹煩相合，故我们可以认 贾政即是曹煩：因此，贾宝玉即是曹雪芹，即是曹煩之子，这一层更容易明白了。”[3]其认为 贾政即曹煩，贾宝玉即曹雪芹。 
把小说视为实录是新红学家能够进行 “曹贾互证” 的前提, 只有小说是历史实录, 那么才能 进行文献和小说之间的双向互证, 但胡适的这种比附在文本与史实上存在种种矛盾: 其一、曹煩 是在曹颙死后才过继给李氏的, “曹颙病故, 蒙万岁天高地厚洪恩, 念其霜母无依, 家口繁重, 特命将曹煩承继袭职。” [4]但书中贾政、贾赦却同时生活在荣府; 其二、曹颙很受康熙的赏 识, “曹颙系朕眼看自幼长成……看起来生长的也鬼梧, 拿起笔来也能写作, 是个文武全才之 人。他在织造上很谨慎。朕对他曾寄予很大的希望。”[5]其被康熙称为是文武全才。小说中的 贾赦却悠游好闲不误正业; 其三、曹颙死后无子，这才使得康熙急于将曹荃的四子曹煩过继给李 氏，但书中 “贾赦却有贾琏、贾琮二子，事实也不合，故知贾赦绝不是曹颙”。[6]其四、按胡 适的比附，贾政继贾赦之后是要袭爵的，贾赦即有子嗣，为何又要贾政袭爵。

胡适对材料明显在进行有选择性的利用, 在有意识的回避一些材料, 对以上种种不合之处视 而不见，这是新红学进行 “曹贾互证” 时最不实在的地方。种种矛盾之处也使得顾颕刚、周汝 昌、徐文漟、宋孔显等对这样的比附疑惑重重, 但他们的始终也没有跳出胡适曹贾互证的大圈 子，只是在此基础上做进一步的推理和修补：其结果是导致更多的假设和想象。

周汝昌先生认为，“红楼梦中之贾母贾太君，实即煦妹，所谓金陵史侯家即李家也。曹寅乃 是贾代善。” “贾赦和贾政本是同生, 都是曹宣的嫡子, ” “贾政是过继的儿子, 贾赦连儿子也 不是。” [7]即贾赦、贾政都不是贾母的亲生儿子，贾赦是以贾母侄子的身份入住荣国府的，但 贾政却是过继到荣府的养子，按周氏的假设贾母偏心于贾政是很自然的，贾赦被逼进偏房也是合 情合理的。

刘心武亦认同周先生的观点。刘心武亦认同周先生的观点。“因为贾赦确实在小说里面是贾 政的哥哥，在生活原型当中也确实是曹煩的哥哥，他和贾政之间他们是亲兄弟，但是他没有过继 给贾母, 明白吗? 他没有过继给贾母, 他怎么能住在荣国府的院子呢, 他当然是在另外一个院落 居住。” [8]刘先生也认为, 贾赦没有住在荣府正院的原因是他压根与贾代化、贾母毫无关系, 连名义上的儿子都不是。

徐文漟对贾赦、贾政二人的关系更是直接提出了两种假设：一、认为作者运用了合身法，贾 赦贾政实为一人，“贾赦、贾政同是影射着曹煩一人。”二、“若是说贾赦代表着曹䙵孙子行中 的另一人的，免求其人，当惟曹氏世系表中赫赫有名的曹颀还算相近。” [9]

还有学者认为, 贾赦虽是长子但为贾代善妾所生, 是庶出。贾政虽非长子却是贾母嫡出。所 以贾赦虽以其长子身份袭承了荣府的爵位, 但始终不能改变庶出的尴䛈地位, 作为贾母亲生嫡出 的贾政固然处处得到贾母的偏袒。主要依据是贾府男子都要择妾，甚至纳妾先于娶妻。[10]

也有学者进行这样的猜想, 贾代善是有前妻的, 贾赦正是贾代善的前妻所生。贾母则是在代 善前妻亡后被扶为正室的, 并生有贾政。所以贾赦虽非贾母所生但亦是嫡出长子, 承袭爵位是理 所当然的事情, 贾母虽对其亲生的贾政疼爱有加, 但能做到的也只能是加以偏爱。

首先以上种种假设与文本处处抵牾:

第一，书中第二回明确写道贾代化、贾母生了两个儿子。“自荣公死后，长子贾代善袭了 官，娶得也是金陵世勋史侯家的小姐（贾母）为妻，生了两个儿子：长子贾赦，次子贾政。” 第二, 书中第三回明确写到贾母是贾赦、贾政的生母： “黛玉方拜见了外祖母-一此即冷子 兴所云之史氏太君，贾赦贾政之母也。”

第三，书中第二回，作者借冷子兴之口说到：“你贵东家林公（林如海）的夫人，即荣府中 赦、政二公的胞妹，在家时名字唤贾敏。” 林黛玉生母贾敏与贾赦、贾政之间是同胞亲兄妹，可 见三人是同父同母。又第三回，贾母对黛玉说到 “我这些儿女，所疼者独有你母......” 既然贾 母是贾敏的生身母亲无疑，那么与其是同胞关系的贾赦、贾政也肯定是贾母所生。 
第四，书中第二十九回，贾母说道：“正是呢，我养这些儿子孙子，也没一个像他爷爷的， 就只这玉儿像他爷爷。” 如果贾政是过继的, 不是贾母的亲生儿子, 贾母又何谈贾宝玉长得像他 的爷爷也就是贾政的父亲贾代善呢?

第五，书中第七十五回，贾赦为影射贾母偏心借用的故事是 “一家子一个儿子最孝顺，偏生 母亲病了”，最后感慨道：“你不知道天下父母心偏的多呢？” 此处母亲显然是暗指贾母，孝顺 的儿子则是指自己，贾赦借用的这个比喻也间接的说明其是贾母亲生。再者，贾赦之所以会抱怨 贾母偏心，恰恰证明了他就是贾母的亲生儿子。

第六，贾赦承袭了荣府的爵位。中国封建社会是靠宗法制维系的家天下的社会，所以香火不 绝的家族观念极强。试问，如果贾赦没有 “儿子” 的名分，连住进荣府的资格都没有，又如何袭 爵？该假设明显与封建社会的文化背景不符。

当以历史比附小说出现矛盾和不符时，历史是已经发生的事实是不可能去否认的，所以只能 通过曲解、忽略小说文本来达到曹与贾的高度统一。所以在历史与文本互证的过程中, 文本往往 处于劣势。胡适、周汝昌、刘心武等既是在索隐小说, 又是在有选择性忽略和曲解文本。可见, “新红学” 的 “自传说” 解决的绝不是 《红楼梦》自身的问题, 其种种假设无非是为了弥合曹贾 比附过程中的矛盾，这使其无形之中变成了小说自身矛盾的制造者。

那么贾赦和贾政在荣府中的宗族地位究竟是怎样的, 贾赦作为荣府爵位的承袭者, 为什么又 会住进荣府的旧园, 他们的关系是不是真的难以理解, 我们依据缜密的小说文本和作者身处的社 会文化背景完全可以得出答案。

\section{3. 小说自身逻辑严密}

\section{1 贾赦向往 “世外桃源” , 主动与荣府隔断。}

书中多次提到贾赦的住处。首先，书中第三回写到： “黛玉夺其（贾赦）房屋院宇，必是荣 府中花园隔断过来的……” , 这说明其住处本是荣府的一部份, 只是人为的用围墙将其隔开。其 次, 书中第十六回, 贾元春才选风藻宫中也提到 “贾赦住的乃是荣府旧园” 。还有书中第七十一 回, 邢夫人这边的费大娘骂王夫人的陪房周瑞家的时, 是 “仗着酒兴, 指着隔断的墙大骂了一阵 子”。从这些方面我们可以看出贾赦所住之处仍为荣府, 只是其故意将其用围墙隔开而已。

从小说中可以看出, 贾赦并没有抱怨过自己住在一隅, 倒是整天在喝酒玩乐, 自己宛如进入 “世外桃源” , 小说第五十三回荣国府元宵开夜宴中写到, “贾母知他（贾赦）在此彼此不便, 也就随他去了。贾赦自到家中与众门客赏灯吃酒, 自然是笙歌聒耳, 锦绣盈眸, 其取便快乐另与 这边不同的。” 贾赦在贾母面前放不开, 母子之间存在的这种别扭其二人也都心知肚明, 而贾赦 自到家中后笙歌聒耳、逍遥快活。这一切都说明贾赦是自愿的, 并非出于某种原因迫不得已才住 在这个角落里。

贾赦虽然从荣府中隔出一隅，但其儿子、儿媳却在荣府当家主事，并且住在荣禧堂后面，与 贾母住在一块, 这也说明贾赦并不是被迫搬出荣府的, 贾赦如若是家族争斗的失败者, 那么其儿 子贾琏的命运应该与其一样被驱逐, 甚至更惨, 而事实却是牫风夫妇住在荣府里当家。书中第二 回对贾赦闲居也早早的做了说明, “长子贾赦袭了官, 为人平静中和, 也不管家务。” 甲辰本在 此句后批写道: “伏下贾琏、风姐当家之文”。可见贾赦作为荣府的继承人, 荣府的事物还是要 处理的, 只不过自己住进 “世外桃源” , 所以其儿子、儿媳就留在荣府办理家务。这犹同宁府一 样，贾敬在外求道炼丹，儿子贾珍在家主持家务。 
另外，贾赦对贾母的偏心颇有微词，有避走之意。书中第七十五回，贾母带领贾府人中秋赏 月, 贾赦在席间讲笑话时说到: “你不知道天下父母心偏的多呢？” 说得贾母怔了半日方回过神 了。这件事说明贾母的偏心是的确存在的，贾赦的暗中抱怨也是有的。

另外, 贾代善虽然已经去世, 但贾母尚在, 所以, 贾母理所当然的住在荣府, 贾赦虽袭承了 荣府的爵位, 但却是整天沉溺于饮酒、纳妾, 这种行为自然是贾母所不愿看到的, 所以时常和贾 母有冲突。书中四十六回, 贾赦就想强纳鹗莺为妾, 遭到贾母怒斥后方罢, 所以贾母并不喜欢贾 赦, 贾赦为了不受约束也不愿住在贾母眼底下, 于是就用围墙在荣府中隔出一角, 自己另辟角门 进出, 这样贾赦的住处就成了一个相对独立的 “世外桃源”。

\section{2 贾母尚在，并未分家的局面导致。}

贾母尚在, 以贾母为中心的荣府并未分家, 《礼记》云: “父母存, 不有私财。”贾赦住在 荣府旧园，与贾政 “同房各羉”，虽单独过活但并未真正分家。

对于兄弟之间别立户籍, 《大清律》继承大明律而有明确规定: “凡祖父母、父母在, 子孙 别立户籍, 分异财产者, 杖一百。” 理由是: “祖父母、父母在, 子孙不得私财, 礼也。” [11] 可见贾母尚在的荣府，不可能出现贾赦、贾政兄弟二人别立户籍、分异财产的情况。

贾赦住在荣府旧园, 琏风却在荣府里当家, 如若现在已经严格分家, 那么琖风必是要与贾赦 住在一处而不可能住在其叔父贾政处。另外荣府上下大小事物是按照定例统一管理的, 女眷、各 房个髻的梯已都是由凤姐按规定统一发放, 各房亲戚婚丧嫁娶的赏银亦是风姐这边支取, 从荣府 财务的管理方式也可以看出荣府并未分家。

凤姐与王夫人走的更近, 对自己的婆婆邢夫人却暗藏區心, 这也是荣府并未分家的左证, 如 若分家, 那么不管风姐对邢夫人有无好感, 面对家族利益分配时两人也会紧紧的抱成团。第六十 一回, 平儿劝风姐: “依我说, 总在这屋里操上一百分心, 终久咱们是那边屋里去的。” 正是因 为风姐是随着王夫人一起过活, 对邢夫人又无好感, 所以时常替王夫人 “这边” 盘算, 而平儿从 贾琏终究是贾赦儿子的角度来提醒风姐, 告诉风姐将来荣府必定是要分家的, 我们是赦老爷那边 的人, 要早替赦老爷这边盘算着, 而不是因为一时好恶而过分的替他人盘算, 可见平儿对风姐的 提醒不无道理。周汝昌先生之所以认为这句话不好懂, 正是没有弄明白赦政并未分家这个大事 实。

贾母既然健在, 那么未分家的荣府自然以贾母为中心, 其住在荣府里是理所当然的事情, 对 贾母的心偏颇有微词的贾赦自然会避而远之。贾政是贾母的小儿子，是比较 “上进” 的士大夫， 贾母自然喜欢跟其住在一起, 后来贾政得了宝玉, 贾母更是把希望放在贾政这边了。

这是赦政当前局面的重要原因之一，未分家就说明贾母仍是荣府财产的统筹人，那么贾赦、 贾政之间的潜在矛盾就不会被表面化，因为未分家前的一切安排都是暂时的、权且的。

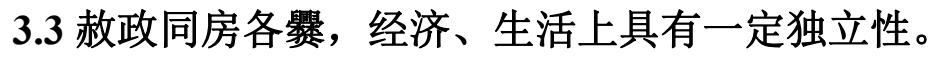

虽然清律规定凡祖父母、父母在, 子孙不得别立户籍, 但是子孙婚娶后要单独过活, 不可能 再与父母以及兄弟住在一起，这就导致了封建大家庭特有的一种现象—— “同房各閧”。同房是 说子孙并未真正分家，仍以祖父母、父母为中心在一个大家庭生活，但各彊说明已是自己一个锅 头做饭, 开始单独过活, 已有相对独立的小家庭。只有明白这种现象, 才能准确解读荣府这个大 家庭。

书中第一百零五回，赵全查抄贾赦时坚持将荣府全部抄没，理由是 “贾赦、贾政并未分家， 闻得他侄儿贾琏现在承总管家, 不能不尽行查抄” 。有意保护荣府的西平王认为: “赦老与正老 同房各綮的, 理应遵旨查看贾赦的家资, 其余且按房封锁”。赵全坚持尽抄荣府, 理由是荣府

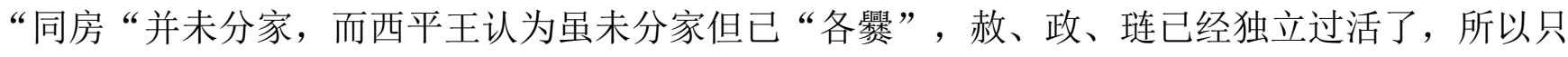


查抄贾赦一人就够了。贾政也向西平王解释到 “祖父遗产并未分过，惟各人所住的房屋有的东西 便为已有”。这虽是有争议的后四十回中的内容, 但至少也说明, 续书已经注意到了封建社会 “同房各藇 “这种特殊现象，并利用其来制造情节。

理解这种局面对我们解读赦政两人微妙的关系有很大的帮助。周汝昌对书中五十五回凤姐的 一句话感到不好懂, “宝玉和林妹妹, 他两个一娶一嫁, 可以使不着官中钱, 老太太自有体己拿 出来。二姑娘是大老爷那边的, 也不算。”其不无困惑的说到：“既是盘算合家大事，怎么单单 二姑娘因是大老爷那边的，就可以不算了呢？” [12]如果明白了赦政之间 “各镙” 的特殊局面, 我们也就明白凤姐正是在利用荣府赦政各自过活、经济相对独立的局面，在银子不足的情况下绞 尽脑汁的去应付荣府的财政，这与西平王为保护荣府而使出的伎俩是一样的，这正凸显了凤姐在 处理上下事物中的谋略，而不存在什么不好懂。

贾赦、贾政、贾琏已是单独过活，都有各自相对独立的家庭，所以贾母过八旬之庆各自为贾 母摆家宴，“初一日是贾赦的家宴，初二日是贾政，初三日是贾珍贾琏，初四日是贾府中合族长 幼大小共凑的家宴。”这没有什么不好懂的。另外贾赦 “自到家中”，指的正是在各藇情况下贾 赦自己单独过活的旧园，这更没有什么不好懂的。

\section{4 邢夫人与凤姐尔虞我诈的 “婆媳关系”加剧了赦政关系的微妙。}

邢夫人与凤姐的关系进一步加剧了赦政关系的微妙。邢夫人与凤姐存在嫌隙的原因来自多方 面: 首先, 邢夫人并无一儿半女, 第四十六回其在与驾尞的对话中提到此事, 但贾赦膝下却有多 子, 所以其很可能是贾赦前妻过世后被扶正的。可见, 邢夫人作为荣府的大太太, 地位有些塩 尬。其次，作为贾家的大儿媳，她却得不到婆婆贾母的欢心，书中第四十六回其向贾母索要驾茑 时而被贾母当面数落。再次, 贾琖大娶了王熙凤, 而王熙凤是王夫人的内侄女, 并且又住在贾 政这边，所以凤姐更容易和王夫人相处，两个人走的近些也是很自然的事情。

邢夫人向来对琏凤没有什么好感, 她对凤姐横行荣府的行为极为不满, 时时伺机报复。当 然, 凤姐对邢夫人也是评价极低, 书中第四十六回写到: “凤姐儿知道邢夫人禀性愚弱, 只知承 顺贾赦以自保，次则婪取财货为自得，家下一应大小事务，俱由贾赦摆布。凡出入银钱事务，一 经她手，便克啬异常，以贾赦浪费为名。”邢夫人在凤姐心目中的形象可见一斑。婆媳之间存在 的嫌隙在第七十四回爆发了, 邢夫人借绣春囊一事向王夫人、凤姐发难, 引起了王善宝家的领着 抄检大观园。

邢夫人的地位以及其与凤姐的嫌隙，一方面使得贾琖、凤姐向王夫人这边倾斜，导致凤姐当 家时处处为贾政这边操心，这也是上面谈到的平儿劝说风姐的原因；另一方面也使得邢夫人更希 望与贾赦避走旧园, 这样以退为进, 一则可以退出激流, 避免直接与王夫人、凤姐处处交锋, 二 则可以伺机对凤姐、王夫人报复反扑。如果说贾赦住进旧园有躲避贾母的意思，那么邢夫人与王 熙凤尔虞我诈的“婆媳关系”又使得此举有躲避儿媳之意。

\section{4. 贾赦、贾政在荣府中的宗法地位}

\section{1 贾赦仍是荣府重大事务的实际决策者。}

贾赦作为荣国府爵位的袭承者, 在宗族中的地位和权威是贾政不能踵至的, 但由于种种原 因，贾政似乎在荣府中扮演主角，但在家族重大事务中，荣府的伦理纲常、长幼尊卑并没有乱， 贾赦仍是荣府的主持者，这一点是毫无疑问的。作者在细节中很注意二人形象的微妙区别。

书中第十六回，贾政过生日，宁荣两府齐聚庆贺，这时六宫都太监夏老爷来传圣旨，“唬的 贾赦等一干人不知是何消息，忙令止了戏文，撤去酒席，摆香案，启中门䟜接。”荣府上下齐聚 为贾政过生日，在这以贾政为主角的宴席上，圣旨一到荣府，作者独独把贾赦的慌乱之态点出 
来，可见作者在细节上用心良苦，夏太监来了大家定是都在慌张，但不管圣旨的内容如何，带头 䟜下来接旨的肯定是贾赦。在这慌乱一团的人中单独把贾赦的名字点出来，与其说作者是为了说 明贾赦作为荣府不肖子孙的无主见和胆小，不如说是贾赦面对未知圣旨时感受到身为荣府主人的 责任重大。作者把贾赦点出来是有深意的, 也暗示了接下来的一系列施令止戏文、撤酒席、摆香 案、启中门、䟜接旨的发号者主要是贾赦。

在建造大观园中，“贾政不惯于俗务……下朝闲暇，不过各处看望看望，最要紧处和贾赦商 议商议便罢了。贾赦只在家中高卧，有芥豆之事，贾珍等自去回明，或写略节; 或有话说，便呼 贾琖、赖大等领命......$”$ 如果说贾政基本上没有参与大观园建造的原因是不惯于俗务, 那么贾赦 更是一个好闲之人，建造大观园是贾府的大事，这件事的定夺自然要归贾赦，所以与其说贾政不 惯于俗务，不如说其不便插手。在紧要处实在不合自己意见了才去找贾赦商议，而此时的贾赦宛 如享乐的集权者，只在家中高卧，其余人或是来报告或是来领命，所有人都围着贾赦转。

第十七回，大观园试才题对额中写到，“这日贾珍来回贾政：“园内工程俱已告竣，大老爷 (贾赦) 已经燋过了，只等老爷（贾政）瞧了......”在这一会中，贾政和宝玉父子上演了红楼梦 中的重要一幕，既是这样，作者也不忘在贾政带领清客来瞧大观园时添上一笔 “大老爷已经燋过 了” , 不管是出于何种原因, 这句话至少表明, 贾赦是有权力先于元妃之父贾政进入省亲别墅

的，原因很简单，因为贾赦是荣府真正的 “嗣法门人”。

书中第十八回元妃省父母，“至十五日五鼓，自贾母等有爵者，皆按品服大妆……贾赦等在 西街门外，贾母等在荣府大门外……” “贾赦领合族子侄在西街门外，贾母领合族女眷在大门外 迎接……”作者两次提到贾赦领合族子侄在西街门外迎候，说明贾政虽是元妃的生父，但省亲大 事还是有贾母和贾赦分别带领女众和男众迎接，严格按照宗法制，在一个把宗法看的如此重的家 族里，可见身为长子又袭承荣府爵位的贾赦在整个荣府的地位和权威。

\section{2 贾赦悠游好闲导致其在家族中的信服力降低。}

贾赦是荣府贾氏的族长，但却一味玩乐、不务正业，这导致其在荣府有威而无信。首先，贾 赦好色嗜酒，连贾母都说他 “放着身子不保养，官儿也不好生去做，成日家和小老婆喝酒”，Y 䇾更是说 “这个大老爷太好色了，略平头正脸的，他就不放手了”。其次，贾赦生性贪婪，为了 五千两银子，竟把自己的女儿迎春典给了孙绍祖，为了几把古扇把石呆子逼得家破人亡。再次， 贾赦教育晚辈的方式更是荒诞之极，作为父亲的贾赦，为了表扬贾琏，竟把自己房里的秋桐赏给 贾琖做妾; 贾琖说了句 “为这点子小事，弄得人坑家败业，也不算什么能为”，贾赦一怒之下竟 然把贾琏打的动不得了; 认为贾琏办事不利就骂到“下流风攮的, 偏你这么知道, 还不离了我这 里” ; 更有甚者, 其竟然奉劝贾环道: “像我们这样的人家, 原不必读什么书, 只要认识几个

字，不怕没有一个官儿做。”

贾政可谓兢兢业业，冷子兴在谈及贾家时认为：“惟有次子贾政，自幼酷喜读书，为人端方 正直。” “礼贤下士，济弱扶危，大有祖风。”林如海更是认为贾政“为人谦恭厚道，大有祖父遗 风，非膏粱轻薄仕宦之流。”

“贾氏三老爷按其不同的所好所长，以各自不同的生存方式活在不同的时间状态里，贾敬活 在将来，贾赦活在当下，贾政活在过去” [13]贾敬一味好道，炼录求仙，爵位早早就让贾珍给袭 了, 所以说贾敬是 “活在将来” ; 而贾赦悠游好闲不务正业, 好色贪婪一味享乐, 所以贾赦是 “活在当下”，其好色贪婪不务正业的习性显然使其在宗族中的信服力、以及权威性大打折扣， 而传统的士大夫贾政虽近迂腐 “活在过去” ，但其精进的处世态度再加上其显赫的地位所以在贾 府上下的信服力自然很高。 


\section{5. 曹氏内部的争斗 “化现” 于小说中}

红楼梦绝不是曹家的纪实史书，但作者的写作过程处处都受到其人生遭际的影响，但以虚构 的小说来比附曹家的历史事实未免有失偏颇, “作家在创作中, 从自己的家世经历、遭逢际遇中 汲取营养是很自然的。尽管我们认为, 《红楼梦》是小说, 绝非象新红学派所主张的是什么曹雪 芹的 “自叙传”，尽管我们现在对作者生平家世的研究还很不全面、不清楚、不到位。” [14]

作者把自己的人生遭际和家族内部的倾车作为一元话题化现于书中，但是化现绝非是重现， 就像融于漂中的一剂黄连, 喝起来口口称苦, 但却道不出何处是黄连: 此处非是, 彼处非是, 但 处处又是黄连。故读者于 《红楼梦》中所见世界时现时隐, 似有还无, 是此又彼。故说贾母是孙 氏而又不是, 说宝玉是雪芹而又显荒唐, 是是非非假假真真, 或许这正是作者想营造的氛围和世 界。所以, 举漂称苦是来品味, 而不是去找黄连, 因为融于水中之黄连早已羚羊挂角遁隐其形。 但形虽不具其味一也, 品《红楼梦》是读者与作者之间心灵的际会, 解的是其中的味, 所以万万 不可以书中之一二猜度历史，更不可以于小说之中探讨历史之形。

\section{参考文献}

[1] 鲁迅: 《中国小说史略》, 长春: 时代文艺, 2009 年第 1 版, 157 页。 [2] 周汝昌: 《红楼梦新证》, 北京: 华艺出版社, 1988 年第 1 版, 41 页。

[3] 胡适: 《红楼梦考证》, 《胡适红楼梦研究论述全编》, 上海: 上海古籍, 1988 年第 1 版, 第 102、103 页。

[4] 故宫博物院明清档案部: 《关于江宁织造曹家档案史料》, 北京: 中华书局, 1975 年第 1 版, 127 页。

[5] 故宫博物院明清档案部: 《关于江宁织造曹家档案史料》, 125 页。

[6] 徐文㳥: 《红楼梦考证的商榷》，《青年界》，1936 年第 9 卷第 4 期。

[7] 周汝昌: 《红楼梦新证》, 北京: 华艺出版社, 1988 年 8 月第 1 版, 44 页。

[8] 刘心武: 《刘心武揭秘<红楼梦>》, 北京：作家出版社，2013 年第 1 版，47页。

[9] 徐文港: 《红楼梦考证的商榷》, 1936 年第 9 卷第 4 期。

[10] 崔文恒: 《也谈 “贾赦位置”》, 《阴山学刊》, 2008 年第 21 卷第 6 期, 20 页。

[11] 马建石、杨玉棠: 《大清律例通考校注》卷六, 北京: 中国政法大学出版社, 1992 年第 1

版, 341 页。

[12] 周汝昌: 《红楼梦新证》, 1988 年第一版, 44 页。

[13] 李劼: 《论红楼梦》, 上海: 东方出版中心, 1995 年, 299 页。

[14] 胡绍常: 《<红楼梦>中的嫡庶亲疏描写与曹雪芹家世研究》, 《红楼梦学刊》, 北京: 2013 年第 6 辑, 第 163 页。 